\title{
La huella del flamenco en el primer cine español
}

\author{
Benito Martínez del Baño
}

Doctor en Ciencias de la Información

Miembro de la Academia de las Artes Escénicas de España

Enviado: $11-11-2020$

Aceptado: $20-12-2020$

\section{Resumen}

Desde edad temprana, el cine español se nutre de las pocas artistas que realmente triunfan en la canción y la radio a principios del siglo pasado, aun con los inconvenientes que ello alberga, al tener que sincronizar durante años película y disco en los pases comerciales. Son un elemento más de la construcción de estos filmes y en muchos casos su eficacia actoral depende más del director que de sus dotes. Son artistas que en la mayoría de casos realizan incursiones esporádicas en el cine. Sólo unas pocas lograrán la continuidad a la hora de participar en películas. Mientras que las mujeres son las que mayoritariamente triunfan y están mejor ponderadas en el terreno de la canción popular, en el campo del flamenco, especialmente son los hombres los que destacan, sobre todo en el cante, y ellas en el baile. La más destacada e internacional de estas actrices es Raquel Meller. Pero, no debemos olvidar a Pastora Imperio, quien, a pesar de estar perdidos sus tres primeros largometrajes, antecede a todas en las lides del cine y destaca entre todos en el flamenco, creando un estilo propio.

Palabras clave: flamenco y cine, Pastora Imperio, Raquel Meller.

\section{Abstract}

From an early age, Spanish cinema has been nourished by the few artists who really succeeded in song and radio at the beginning of the last century, even with the disadvantages that this harbors, having to synchronize film and record for years in commercial shows. They are one more element in the construction of these films and in many cases their acting effectiveness depends more on the director than on their talents. They are artists who in most cases make sporadic forays into the cinema. Only a few will achieve continuity when it comes to participating in movies. While women are the ones who mostly triumph and are better weighted in the field of popular song, in the field of flamenco, it is especially men who stand 
out, especially in singing, and they in dancing. The most prominent and international of these actresses is Raquel Meller. But, we must not forget Pastora Imperio, who, despite her first three feature films being lost, precedes all of them in filmmaking and stands out among all in flamenco, creating her own style.

\section{Introducción}

En España se posee un pensamiento cinematográfico alejado de la grandilocuencia de las producciones hollywoodienses y, a pesar de intentar emularlas, no se consigue alcanzar sus pasos, siendo uno de los motivos la escasa exportabilidad del cine español en los primeros tiempos, achacable en buena parte a la deficiente producción de nuestras películas, centradas y concentradas en torno a un falso andalucismo, y después a una españolidad ficticia. Pero también resulta extraño este pensamiento, ya que los americanos adaptan novelas y obras teatrales o musicales, que bien podrían ser comparables técnica y literariamente, a las obras literarias y audiovisuales adaptadas en nuestro suelo, incluso a las adaptaciones de zarzuelas. Si bien parece que lo foráneo es "bueno" y lo nuestro, "malo", en los referentes de calidad.

La paralización profesional del cine de corte folclórico según los acontecimientos políticos y la pérdida de interés del gran parte del público tras los primeros años de actividad cinematográfica, influyen en que se intente dotar de respetabilidad al cine y alejarlo de la concepción amateur de los inicios. Se lleva a cabo el intento influenciado el cine por escritores y pensadores del momento quienes, aun no estando relacionados con la Cinematografía, algunos escriben guiones o dirigen su propia novela homónima para el cine impulsados por su importancia en el espectro literario y porque es una nueva vía para llegar al público. Lo mismo que en el mundo artístico anglosajón. 


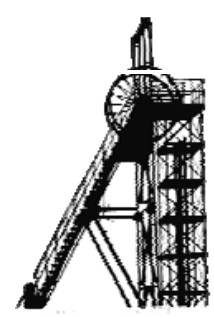

Pero, aún en la actualidad, y dentro de este galimatías, sigue existiendo una extraordinaria confusión sobre cuál es realmente la primera cantante española, que no actriz, que se pone al frente como protagonista de un largometraje, y, por tanto y también, sobre cuál es la película de corte folclórico muda, sincronizada, sonora, hablada, cantada, hablada/sonora, y hablada/sonora/cantada; es decir, que reúna una, varias o todas las características, teniendo en cuenta incluso el paralenguaje, y presentando los problemas técnicos propios de su tiempo a la hora de su exhibición en salas comerciales. En estas cuestiones nos vamos a centrar a partir de ahora.

\section{La música antes y con el cine}

Cuando la música culta entra en declive o comienza a relegarse a las clases cultas tras el inicio de la expansión industrial, las estructuras compositivas en la duración de los espectáculos empiezan a transformarse rápidamente, igual que la sociedad. Si los espectáculos de música culta ofrecen una duración de varias horas mediante una sucesión de composiciones, y muestran unidades de creación dirigidas a las élites, al producirse la expansión cultural comienza a ganar terreno la música popular, tipo de composición que persigue un acercamiento a un público mayoritario. Se produce el choque de la élite con el pueblo llano, y éste último comienza a ganar terreno. Así, la canción, cuya duración disminuye ostensiblemente hasta una media de tres o cuatro minutos por tema, comienza a manifestarse como una forma identitaria de la clase inculta o analfabeta, es decir, el espectador colectivo que vive en núcleos urbanos.

Y poniéndonos en lo peor, a los pocos años de su nacimiento se ha vulgarizado el entonces gran invento del Fonógrafo, y los divos del cante comienzan a perpetuar sus voces en los discos. En los teatros prima entonces el género de variedades, donde el flamenco es el número de fuerza; y en cuestión de artistas, cantantes y bailaoras, Custodia Romero La Venus de Bronce, entre 
otras esculturales bailarinas rivalizan con la gran Pastora Imperio, de quien hablaremos largo y tendido más adelante, en España la mayor estrella de su tiempo. Son años en que no va a tardar en surgir otro nuevo invento, la radio, y con él viene el fin del cante en vivo y en directo, como hasta entonces se ha conocido. Por su parte, Antonia Mercé La Argentina, quien responde al nombre de Antonia Mercé y Luque (Buenos Aires, Argentina, 1890 - Bayona, Francia, 1936), consigue electrizar a los públicos españoles y extranjeros con la magia de sus danzas. Bailarina y coreógrafa y virtuosa en el uso de las castañuelas o palillos. Nace con ella y definitivamente el ballet español.

Igualmente a lo sucedido con el Fonógrafo, el Cinematógrafo y las películas van a perder el interés del vulgo de casi toda clase y condición y entran en declive a los pocos años de su nacimiento, ya que comienza el público a percibir las películas como una deformación del teatro y a considerarlas "teatro filmado".

\section{El flamenco y lo que trajo consigo}

Los cantes flamencos constituyen un género poético y lírico en sí mismos e incluyen una determinación superflua al emplear en algunas descripciones vocablos redundantes para dar a la oración un sentido completo, añadiendo, además, expresividad a lo que se dice. Las letras de los cantes puramente gitanos poseen tres elementos fundamentales: raza, familia y amor.

Hace dos siglos y medio, en el campo del flamenco se produce una curiosa similitud entre los números y cuadros de los cantaores flamencos y la zarzuela, música preponderante entonces. El primero marca una vía paralela a la música culta para el cultivo de la canción unipersonal

Se funden con los siglos varias culturas en España. Los moriscos, a causa de su potestad perdida; los judíos, porque se creen el pueblo elegido por Dios; los bandidos y mendigos castellanos porque su raza se cree justiciera del 


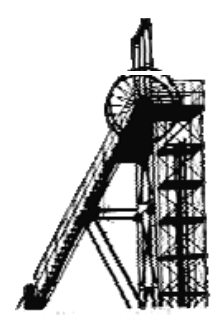

mundo; y los gitanos, por su jactancia de pertenecer a una casta de sangre real cuya milenaria estirpe se remonta a los tiempos anteriores a Jesucristo. Estos, los gitanos aprenden, a su vez, los bailes, canciones y romances de los otros proscritos. Y de este conjunto de personas surge allá en las guaridas serranas la aleación singular del estilo "flamenco" de vivir. Pero también surgen de ese cónclave cultural las primeras fusiones del cante jondo, un estilo peculiar de interpretar gitanamente las canciones moriscas, los cánticos sinagogales y los cantares castellanos. El artífice de este estilo es el gitano, y los ámbitos de esta música nueva y viejísima, honda y plañidera, serán en adelante la cárcel, la galera, la venta y el prostíbulo. A todo esto España ha comenzado a declinar.

Nos acercamos al siglo XIX. Fernando VII es el precursor del señorito aflamencado. Y, resulta curioso cómo más adelante se hará marqués a un flamenco. Sirva el caso del cantaor, Porrinas de Badajoz, cuyo nombre es José Salazar Molina (Zalamea de la Serena, Badajoz, 13-01- 1924 - Madrid, 1977), cantaor flamenco que destaca por su fuerte personalidad e intuición para fabricarse todo un marketing con su vestuario, gafas y clavel en la solapa, que lo hacían inconfundible. Pues bien, fue Marqués de Porrina. El título de marqués se lo dieron en Madrid en una noche de juerga precisamente otro Marqués también nombrado a dedo, el de Villaverde (yerno de Franco), que fue quien le bautizó. Primero le dijo: «-Si esta noche cantas bien te vamos a hacer marqués». Porrina estuvo sensacional y como es habitual en este tipo de fiestas privadas, se le otorgó el título de Marqués de Porrina, que desde entonces ostentaría con orgullo y al que revistieron con toda seriedad de heráldica propia, con un escudo en el que aparece un telón, un as de bastos, el clavel, las gafas y la columna y el león en recuerdo a Badajoz, y donde debajo se puede leer una frase en latín: «Gladio Voceque Vivo».

Los andaluces de los bajos fondos copian ya las coplas, coplillas y bailes de los flamencos o gitanos. Empieza a marcarse en el ámbito burdelesco y tabernario la figura del cantaor gitano que cobra por cantar y se gana la vida 
con su arte. Los toreros de fama hacen de mecenas de los artistas flamencos, quienes ya han comenzado a ser artistas profesionales. Poco después surgen los primeros cafés cantantes. En aquellos cafés se forjan los moldes clásicos de lo jondo y en el ambiente, entre bohemio y artesano de aquellos locales, pontifican los que dicen saber más sobre tal o cual mérito del zapateado de la bailaora o la pureza de la copla que entona el cantaor. Son los llamados "cabales". Es la Edad de Oro del Flamenco, que no tarda en conquistar el favor del público de Madrid, para extenderse desde allí a otras ciudades de toda geografía española. Tiempo después gozará de culto allende nuestras fronteras.

\section{Cafés cantantes}

Los cafés cantantes son fundamentales en España para el pináculo del flamenco, es decir, para entenderlo y para saber de su expansión. Aunque se suele hablar de los cafés cantantes como sinónimo del café-concierto o denominados erróneamente por su grafía francesa, café-concert, lo cierto es que no son "hermanos". En/os primeros prima el flamenco, mientras que en los segundos se cultivan los géneros frívolos y el cuplé. La aparición de los cafés cantantes posee un carácter esencialmente comercial y lucrativo para sus dueños. Con su auge se busca dar a conocer los cantes y bailes antiguos de Andalucía esencialmente, mediante la figura de los cantaores y bailaores profesionales, cantes que hasta la aparición de estos locales, no se manifiestan, interpretan o ejecutan fuera de pequeños círculos eminentemente familiares. Al trascender de esta forma la ejecución se permite que un nutrido grupo de espectadores pueda presenciar los cantes y bailes. Por lo general, los cafés cantantes, poseen en su tiempo un aspecto de café antiguo, de barrio, de los que aún queda alguna muestra arqueológica hoy día sin convertir aún en banco, un tablao y muchos espejos. El espectáculo que en ellos se exibe, se compone de dos partes: en la primera, actuaban las "boleras". Existe, por aquel entonces, una marcadísima diferencia entre lo bolero y lo flamenco, entre lo 


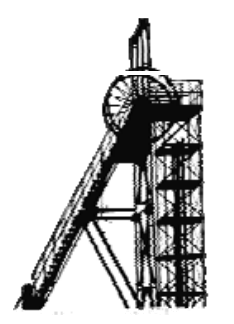

español y lo jondo, de tal forma que ninguna bolera hubiese osado bailar con guitarra ni ninguna "bailaora" con los compases de la orquesta. La segunda parte del espectáculo consta únicamente del cuadro flamenco en su manera más tradicional y clásica. Permiten estos locales intensificar la práctica del arte flamenco entre los profesionales y mantienen su auge en la segunda mitad del siglo XIX, llegando su decadencia en los años veinte del siguiente siglo. Representan igualmente el lugar en que el cante, tras una primera época de exhibición restringida, aparece ante un público numeroso. En ellos el cante dejar de ser un arte minoritario para alcanzar difusión y arraigo populares. Como hemos visto, estimulan la aparición de los cantaores profesionales, es decir, de los profesionales del cante. El problema surge para y con los puristas del flamenco y los "cabales", para quienes si el cante viene a ser un tema que fuese interpretado por "funcionarios" y no por espontáneos que saben cantar y por eso suben a un escenario, por pequeño que sea, y se exponen al público.

Los cafés cantantes que existen entre los años 1847 y 1920 surgen, por un lado, por el auge toman en Europa los cafés con espectáculos musicales, no sólo como entretenimiento sino también como inquietud artística y cultural. Por otro, por la necesidad de canalizar la expansión cada vez más pujante del costumbrismo andaluz. Para la historia del flamenco creemos que el hecho es positivo, no sólo por su evolución, sino por su limitación al definir bien los géneros que integran el espectáculo. Por un lado la escuela bolera, y por otro lo autóctono andaluz al integrarse al nuevo género flamenco, con estilos que se crean y perfeccionan, quedando la guitarra como instrumento único y definitivo. $\mathrm{Y}$ eliminando hasta casi el olvido algunos estilos musicales, canciones andaluzas y ciertos instrumentos de acompañamiento: panderetas, violines, bandurrias, que por cierto ahora vienen a incorporarse de nuevo. $Y$ aquel naciente flamenco no tarda en llegar a todos los rincones de España por la labor de difusión que consiguen los cafés. Es tal la aceptación, que rara es la provincia española que no cuenta con algún café cantante en su haber. Por las 
salas y tarimas de los cafés cantantes pasa junto a todo lo mejor y peor del género flamenco, pero también cupletistas; circo, magia y teatro; bailes americanos, franceses, exóticos, de agarrado y de escuela bolera; lidia de becerros; comparsas, chirigotas y coros; audiciones de Fonógrafo y cómo no, algunos pases de Cinematógrafo con la película más popular del momento.

Hasta nuestros días, la época en que existen los cafés cantantes es tenida en cuenta como la "época dorada del flamenco", durante la cual se crea una especie de reglamento, y todo lo que surge después fuera del mismo se considera heterodoxo, no se teniéndose en cuenta como puro. En España, los cafés cantantes de Sevilla marcan en aquellos años la pauta que seguirán los demás cafés en territorio patrio.

\section{Géneros frívolos y cuplé}

Por su parte, con respecto a los géneros frívolos, en Barcelona, hacia 1890, surge, con cierta timidez al principio y en los cafés conciertos, un tipo de canción, importada de Francia, con letra picaresca o procaz y musiquilla retozona y trivial. Luego, es en Madrid donde prolifera la novedad y se extiende después a coliseos conocidos y a otros que se construyen expresamente. Se trata del cuplé de tipo pícaro.

$Y$ es que a principios del siglo $X X$, la cultura española achaca un excesivo afrancesamiento, como décadas atrás acusa una descomunal italianización, ya que el concepto de espectáculos y lo que engloba genéricamente el conceptomarco de la cultura de entonces se manifiestan en España importados directamente desde la vecina Francia.

Con el cuplé, surgen figuras de mujer que, una vez artistas, traspasarán el fervor del público, la memoria colectiva e incluso las ondas de la posterior radio y las imágenes de películas en la pantalla grande. 


\section{Pastora Imperio}

Pastora Rojas Monje (Sevilla, 1885 - Madrid, 1979), cantante y actriz, fue sobre todo la bailaora más importante de su tiempo y durante décadas. Vive la Monarquía, la II República y el Franquismo. Amiga de intelectuales de la época, Julio Romero de Torres la pinta en lienzo, y Mariano Benlliure le realiza una extraordinaria escultura. También escriben sobre su figura los autores más relevantes de la época, atraídos por su característica personalidad. Así se convierte en icono y objeto de admiración social. Pastora obtiene en vida diversas condecoraciones, entre ellas el Lazo de Dama de la Orden de Isabel la Católica, que le es concedido en 1957.

Nacida en el barrio de la Alfalfa, esta sevillana es hija de la bailaora Rosario Monje, apodada "la Mejorana", quien no quiere enseñar a bailar su hija, y de Víctor Rojas, sastre de toreros. Es, además, bisabuela de la popularísima actriz Pastora Vega, expareja del también actor Imanol Arias. Estudia en la academia de Isabelita Santos en Sevilla, ya que, ella misma es quien declara que su madre no quiere enseñarla a bailar. Antes de Pastora, su madre es considerada la mejor bailaora que hasta entonces ha dado Cádiz. Contrae matrimonio con el torero Rafael Gómez "el Gallo", el veinte de febrero de 1911, y deja los escenarios a petición de su marido. El matrimonio dura ocho meses, los mismos que Pastora se retira del arte.

Cuando aún no cuenta la mayoría de edad, en 1901, comienza a trabajar y su primer nombre artístico en solitario es Pastora Rojas, incluso alguien la bautiza como Pastora "la Grande", si bien tras verla actuar en el Salón Actualidades, el ilustre Premio Nobel de Literatura (1922), Don Jacinto Benavente y Martínez (Madrid, 1866 - Galapagar, Madrid, 1954) genial y prolífico dramaturgo, director, guionista y productor cinematográfico. exclama: «-Esta niña es un verdadero imperio». Desde ese día su nombre artístico definitivo es el que todos conocemos y que permanece aún a pesar de la losa del 
tiempo. Debuta en solitario en 1905 y pronto se la incluye entre las estrellas del momento junto a "la Fornarina", cupletista que responde al nombre de Consuelo Vello Cano, (Madrid, 1884 - Madriud, 1915); Consuelo Portela Audet, "la Bella Chelito" (Cuba, 1885 - Madrid, 1959); y Amalia Molina, cuyo segundo apellido es Pérez (Sevilla, 1881 - Barcelona, 1956). Pastora canta, baila y recita, se convierte en un mito del flamenco, siendo lo más destacado de su baile, su "braceo", su baile con los brazos como mejor y mayor parte de su expresividad artística, que es lo que la eleva a la categoría que aún hoy posee, más conocida que su cante. Igualmente tiene una personalidad arrolladora, expresividad y fuerza en el escenario, además de una elegancia innata para mover la bata de cola. Y es que una de las grandes novedades escenográficas de Pastora es que ésta pone de moda el baile con bata de cola. Seis décadas después, Rocío Jurado es quien depone la bata de cola sólo para los números flamencos de sus espectáculos, luciendo trajes de noche para cantar sus baladas.

En su repertorio introduce la "flamenquería", es decir, la interpretación de sus canciones con un toque flamenco en la composición poniendo de moda el baile con bata de cola y peineta. Rocío Jurado es, tras Pastora Imperio, la primera artista que destina la bata de cola y el traje de lunares, que originalmente se utilizaba en la feria de ganado de Sevilla, únicamente para los números flamencos de sus espectáculos, luciendo prioritariamente trajes de noche en sus recitales. Lo mismo sucede con la peineta.

Entre los temas del ramillete de canciones de Pastora, destaca un cuplé del maestro Font de Anta titulado La nieta de Carmen, que bien podemos reseñar como uno de los pilares de lo que después vamos a conocer, dentro de la "canción popular", como copla, tal y como nos ha llegado hasta nuestros días. La música también une a Pastora con Miguel de Molina, quien pone voz a las dos versiones (compuestas en 1934) que existen de La bien pagá (PerellóMostazo) aunque graba la segunda de las mismas. Sobre la primera su propio autor, el murciano Ramón Perelló y Ródenas, afirma que resulta un rotundo 


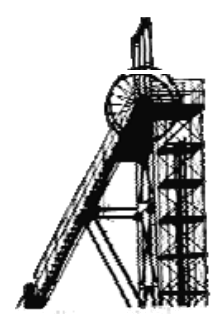

fracaso en su estreno y ha de retocarla. Éste también le canta la farruca-zambra, Soy de la raza calé, tema compuesto en 1935 y conocido también como Herencia gitana (Perelló - Cantabrana - Mostazo) y escrito originalmente para Pastora Imperio.

En el cine también es una pionera y lo sabe. Contratada por el productor José Carrera para protagonizar una serie de filmes, el primero de los títulos es La danza fatal (1914), obra pionera por lo primitivo de su realización y extraño de su planteamiento que muestra el característico braceo del que Pastora Imperio hace gala. Un insólito filme dirigido por José de Togores, que obtiene notable éxito comercial, salvando a la productora Argos Films de la quiebra. Lo cierto es que el resultado final no es el deseado por director y productor y, es por los retoques que realiza Ramón de Baños, por lo que finalmente se estrena el filme en salas comerciales. Canta Pastora el tema La pena, pena, que se incluye en los intertítulos del filme.

Tengo yo una pena, pena que no se cura con ná, que me está enterrando en vía y me tiene que matar. (Lapuerta)

Se hace muy importante destacar en este punto que Pastora es, históricamente, la primera artista folclórica en protagonizar una película en formato largometraje, si bien por la duración de La reina de una raza (1914), de sesenta y cuatro minutos, podríamos también incluir este título en la categoría de mediometraje. Se hace ahora importante señalar que, aunque, habitualmente, se señala a Raquel Meller como la primera artista folclórica en colocarse ante la cámara, deseamos dejar claro, que honor y mérito corresponden a Pastora Imperio. Le siguen en su filmografía. La reina de una raza (1917) y Gitana cañí (1917), los dos títulos dirigidos por Armando Pou. Estas tres películas, a día de hoy, están perdidas, por lo que hemos tenido que recurrir, principalmente, a fuentes hemerográficas y a la familia de la artista. 
Por su parte, su filmografía sonora queda como sigue: María de la O (1936) a las órdenes de Francisco Elías Riquelme, y junto a Carmen Amaya en su primer papel principal. Encontramos a Pastora como Soledad "la Itálica", madre adoptiva de María de la O. Charo Vega, unigénita de Pastora Imperio, interviene con el nombre artístico de "Rosario Imperio", en el papel de Mari Cruz. Supone este filme un melodrama racial encuadrado dentro del andalucismo, con ambientación musical del maestro Quiroga. Sigue La marquesona (1940) dirigida por Eusebio Fernández Ardavín. Después, Canelita en rama (1943) de Eduardo García Maroto, superproducción con Juanita Reina, cuyo nombre completo es Juana Reina Castrillo (Sevilla, 1925 - Sevilla, 1999) y ambientada en Andalucía con guión de Antonio Guzmán Merino y con Pastora Imperio en el papel de tía Consolación, interpretando un tanguillo. El protagonismo, como decimos, es de Juanita Reina. Pocos años después se filma El amor brujo ${ }^{1}$ (1949) a las órdenes de Antonio Román con argumento original de Gregorio Martínez Sierra y guión de José María Pemán y Francisco Bonmatí, María de la O (1957) de Ramón Torrado. La artista participa también y finalmente mediante colaboración en Duelo en la cañada (1959), trivial drama de corte andaluz de Manuel Mur Oti que no interesa a crítica y público. Mary Esquivel, Javier Armet y Mara Cruz obtienen los principales papeles. El argumento gira en torno a Soledad, una artista a la que un rico terrateniente intenta violar en su/camerino, pero ella lo mata. Un mayoral, Ramón, enamorado de Soledad la ayuda a escapar y buscan refugio en la finca de Mendoza, quien también se enamora de la artista. Los dos hombres han de batirse en duelo, con la consiguiente muerte de uno de ellos.

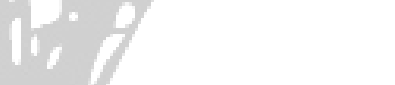

1 El amor brujo es compuesto en 1915 por Manuel de Falla para que la obra fuese interpretada por Pastora Imperio, quien la estrena en el Teatro Lara de Madrid, y es la artista quien también participa en la versión cinematográfica, ésta con argumento original de Gregorio Martínez Sierra y guión de José María Pemán y Francisco Bonmatí. Una nueva versión antes de la realizada por Carlos Saura en 1986 sería protagonizada por Antonio Gades y Josefa Cotillo Martínez La Polaca, en 1967 y con dirección de Francisco Rovira Beleta. 
Sobre Pastora se ha escrito mucho por los autores más relevantes de la época. Todos sentían es atracción característica de su personalidad. Existen numerosos poemas donde se pone de manifiesto la figura de la artista. He aquí el que le dedican los hermanos Serafín y Joaquín Álvarez Quintero:

Tras las alegres vueltas de un paseo, ostentación del garbo y la majeza, la bella danza a dibujar se empieza con valiente y armónico braceo. Fingen las manos mágico aleteo, muévese altiva la gentil cabeza y recorre un impulso de fiereza el cuerpo aquel que modeló el deseo. $Y$ del postrer desplante al recio empuje, ruedan los peinecillos y las flores por el tablado, que a sus plantas cruje.

(Hnos. Álvarez Quintero)

\section{Raquel Meller}

A Francisca Marqués López (Tarazona de Aragón, Zaragoza, 1888 Barcelona, 1962) -hermana de la también artista y actriz de compañía, hoy ignota, Tina Meller-, su seudónimo le viene de un novio germano apellidado Moeller, que ella españolizó en Meller. La elección del nombre, únicamente porque le resulta atractivo. Aunque es una dama de bajo nivel cultural, goza de fama de mujer de fuerte temperamento y carácter, y tiene una vida muy agitada, marcada por el escándalo y la tragedia. Siendo aún muy pequeña es llevada a Montpellier (Francia), donde reside una tía suya que es monja y quien la educa. La niña canta en el coro del convento, donde ya hace gala de su predisposición musical. A los doce años regresa con sus padres, quienes se han instalado en Barcelona.

Considerada la primera cantante convertida en actriz folclórica nacional, estamos dirimiendo que esto no es así, ya que tampoco es la primera artista folclórica que participa en el cine, porque la primera de las artistas de su generación en interactuar con la cámara no es otra que Pastora Imperio. Por 
tanto, la considerada primera, manifestamos y dejamos claro que, históricamente es la segunda. Imperio, primera. Meller, segunda. Aunque ambas comiencen cantando cuplés y Pastora Imperio después se decante por el flamenco, y Meller triunfe a escala internacional con sus cuplés serios, alejándolos de la frivolidad de sus letras iniciales. Con quince años comienza a trabajar como modista en un taller de costura, lugar donde suele cantar a sus compañeras, hasta que una cupletista profesional hoy olvidada, Marta Oliver, es quien realmente la descubre, anima e incluso tutela para que comience su carrera como artista. Debuta como cantante en 1911 en el Teatro Arnau de Barcelona, siendo en sus inicios conocida como "la Bella Raquel". Sus interpretaciones otorgan al cuplé un aceptable nivel social y lo alejan del género ínfimo. Los grandes éxitos de la Meller son El relicario (1918), con letra de Oliveros y Castellví, y música de Padilla, que supone un pasodoble estrenado por Mary Focela y reestrenado en 1918 por Raquel Meller, y La violetera (1930), compuesta la letra por Montesinos y la música por el maestro de Almería, José Padilla Sánchez. Estos dos magníficos ejemplos de canción no son estrenados por la Meller, si no que es ella quien los populariza en nuestro país, además de París y otras capitales europeas, como también en Nueva York.

En cuanto a la filmografía de esta completa artista, la primera y única película muda protagonizada por Raquel Meller y rodada en territorio español, responde al título de Los arlequines de seda y oro (1918-1919), basada en la obra en cinco actos de José Amich Bert Amichatis, Josep María Castellví y Armand Ontiveros, con música de Isidre Rosselló y Joan Aulí Padrós, estando dirigida por Ricardo de Baños, en la Royal Films, título que consta de tres episodios: El nido deshecho, La semilla del fenómeno y La voz de la sangre. Para la película se filma ocasionalmente una corrida de toros organizada en la Real Maestranza de Sevilla, en cuyo cartel figuran Rafael Gómez Ortega El Gallo (ya exmarido de Pastora Imperio), Juan Belmonte y Rodolfo Gaona. Supone un ambicioso filme que cuenta con el atractivo añadido de mostrar la primera aparición de Raquel 


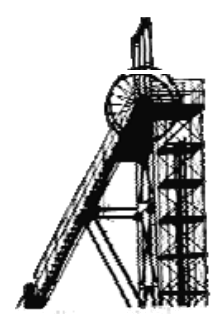

Meller en la gran pantalla. Ésta es una película de amores, toros y tintes dramáticos, rebautizada en 1923 como La gitana blanca, ocasión para la que se eliminan las escenas taurinas y se elabora un filme más exportable comercial e internacionalmente.

Continuamos con sus dos mejores y más conseguidas películas, como son la versión muda de Henry Roussel de Violetas imperiales (1922) y Carmen (1926) de Jacques Feyder, ambas rodadas en Francia. Al estar rodadas en territorio foráneo, las descartamos aquí, si bien aprovechamos para recordar su filmografía francesa, dentro de la que hay que destacar: Les oprimés (Rosa de Flandes) (1922) y La terre promise (La tierra prometida) (1924) ambas de Henry Roussel, La ronde de nuit (Ronda de noche) (1925) y Nocturne (Nocturno) (1926) estas dirigidas por el hoy olvidado director Marcel Silver y La venenosa (1929) Roger Lion, basada en la novela de José María Carretero. Después protagoniza una segunda versión de Violetas imperiales (1932) dirigida también por Henry Roussel para el cine sonoro, suponiendo este título la única filmación sonora en que participa la Meller, y en 1936 da comienzo el rodaje de Lola Triana (1936) película escrita por José María Pemán, que va a ser dirigida por José Santugini, siendo la producción interrumpida por la Guerra Civil y no llegando a concluirse. En el/reparto figuran, además de Raquel Meller, José Nieto, Pablo Álvarez, María Calvo y Conchita Leonardo.

Retrocedamos en el tiempo, ya que se produce un hecho muy importante en 1926, en el que Raquel Meller es considerada una pionera, cuando realiza en Nueva York un cortometraje con cuatro temas musicales y a las órdenes del director francoamericano Marcel Silver, donde graba sus canciones más famosas. Se trata de cuatro filmes cortos en un rollo, sobre cuatro canciones, Tarde de Corpus, La mujer del torero (junto a René Cardona ), El noi de la mare y Flor del mal, todas rodadas para que la Fox pruebe su nuevo sistema de sonido Movietone y para ser sincronizada la imagen con el disco en las proyecciones. Esta serie de cortometrajes se estrena en Nueva York en el veintiuno de enero 
de 1927 y actúa como preámbulo sonoro del filme mudo El precio de la gloria (1926) (What price glory?, en inglés) dirigido por Raoul Walsh, comedia de corte romántico protagonizada por Victor McLaglen, Dolores del Río y Edmund Low. En España son estrenados en 1929, tres años después de su realización. Son rodados, casi con total seguridad, en el sistema Phonofilm, patentado por Lee De Forest.

Pero Meller tampoco es pionera en este hecho del cine sonoro. Hemos de reseñar en este punto el importantísimo hecho de que estos cortometrajes arriba reseñados, son de corte y factura idénticos a los rodados con anterioridad por Conchita Piquer, nombre artístico de Concepción Piquer Lónez (Valencia, 1906 - Madrid, 1990), quien en 1923, y a los diecisiete años de edad, graba una película de once minutos que incluye cuatro temas musicales, a las órdenes de Lee De Forest. Piquer conoce en Nueva York al ingeniero Lee De Forest, quien patenta el sistema Phonofilm, el experimento definitivo que este pionero realiza para sincronizar imagen y voz y que, con las consiguientes mejoras técnicas, pervive en nuestros días. La artista se inicia en su andadura cinematográfica con los temas popularizados en su primera época e incluidos en la película de once minutos en formato cortometraje de un rollo con cuatro canciones, en las que Piquer actúa, canta y baila las piezas mencionadas del repertorio ibérico de entonces, y que mencionamos a continuación: Farruca torera, Del diablo o del demonio, el fado portugués Ainda mais, y la jota aragonesa, Niña, ¿de qué te las das?, tema que tiempo atrás populariza "la Argentinita":

Si quiere la mujer que un hombre se vuelva loco por ella, que se aprenda de memoria esas cuatro o cinco reglas.

Lo primero que ha de hacer es ser llana y natural porque el orgullo es un traje que no le sirve de ná"2.

(Manuel Susillo y Font de Anta)

2"Según Salaün (1990: 186), creación original de "la Argentinita”. 


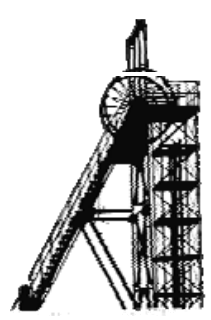

En la filmación, interpretando este tema, Conchita pone los brazos en jarras y aconseja a las niñas como ella, lo que hay que hacer para encontrar marido. En este momento la Piquer triunfa en Manhattan (Nueva York). Supone el cortometraje la primera filmación en que participa una artista española realizada en el sistema de cine de De Forest, después y como ya hemos visto, en este mismo formato, entonces pionero, de película participa Raquel Meller, en el que la banda sonora está sincronizada con la imagen, sistema que todavía hoy pervive con las obvias mejoras técnicas.

Por tanto, Raquel Meller es la segunda pionera española en cuanto a los experimentos del sonoro, al conseguir que sus cortometrajes rodados en 1926 se proyectasen con el sonido sincronizado de las canciones incluidas.

\section{Conclusiones}

No todas las actrices provienen del mundo de la canción, ya que para algunas, ésta supone una actividad sobrevenida tras sus primeras incursiones en la pantalla grande. De hecho, alcanzan gran notoriedad social para obtener un provecho profesional, social y económico.

Igualmente las primeras piezas flamencas filmadas se pueden encuadrar en el primer concepto, y los cantables de zarzuela, en el segundo.

En contra de lo aceptado comúnmente, la primera actriz folclórica en colocarse delante de la cámara cantando no es Raquel Meller en Los arlequines de seda y oro (1918-1919) de Ricardo de Baños, sino Pastora Imperio en La danza fatal (1914) dirigida por José de Togores. No cabe duda de que el hecho de que el segundo título esté perdido ha facilitado la mayor difusión del primero.

También destacar que, mientras Meller ya cultiva el género folclórico cuando se presenta en pantalla grande, Imperio destaca en el terreno del cuplé.

Pero no olvidemos que Conchita Piquer fue la tercera. Aunque eso es otra historia. 


\section{Bibliografía}

Blas VegA, José y Ríos Ruiz, Manuel (1988). Diccionario Enciclopédico Ilustrado del Flamenco. Madrid: Ediciones Cinterco.

Cobo GuZMÁN, Eugenio (2013). El flamenco en el cine. Sevilla: Signatura Ediciones

García Matos, Manuel (1987). Sobre el flamenco. Madrid: Editorial Cinterco.

GUICHOT Y SIERRA, Alejandro (1922). Noticia histórica del folklore. Orígenes en todos los países hasta 1890. Desarrollo en España hasta 1921. Sevilla: Hijos de Guillermo Álvarez.

LAFUENTE AlCÁNTARA, Emilio (1865). Cancionero popular (tomo I). Madrid: Carlos Bailly-Bailliere.

Pineda Novo, Daniel (1991). Las folklóricas y el cine. Huelva: Festival de Cine Iberoamericano de Huelva.

RomÁN, Ignacio (2006). Crónicas de la copla. Madrid: Fundación Autor.

Román, Manuel (1994). Canciones de nuestra vida. Madrid: Alianza Editorial.

ROMÁN, Manuel (2000). La copla: la canción tradicional española, la tonadilla, sus orígenes populares, los mejores intérpretes. Madrid: Acento Editorial.

RomÁn, Manuel (1993). Memoria de la copla. La canción española de Conchita Piquer a Isabel Pantoja. Madrid: Alianza Editorial. Madrid.

SAla NogueR, Ramón (1990). El cine en la España republicana durante la Guerra Civil (1936-1939). Bilbao: Ediciones Mensajero.

SALAÜN, Serge (1990). El cuplé (1900-1936). Madrid: Espasa-Calpe.

SERRANO, Alfredo (1925). Las películas españolas (Estudio crítico-analítico de desarrollo de la producción cinematográfica en España. Su pasado, su presente y su provenir). Barcelona: Autor.

VAlls GorinA, Manuel y PADrol, Joan (1990). Música y cine. Barcelona: Ultramar Editores.

VAlverde, Salvador (1980). El mundo de la Zarzuela. Madrid: Palabras S.A. Editorial.

VÁZQUEZ MonTALBÁN, Manuel (1974). Cancionero general (1939-1971). Barcelona: Editorial Lumen. 